\title{
GLP-2 receptor expression in excitatory and inhibitory enteric neurons and its role in mouse duodenum contractility
}

\author{
L. CINCI, ${ }^{\star}$ M. S. FAUSSONE-PELleGRINI, ${ }^{\star}$ A. ROTONDO,$\dagger$ F. MUlÈ $\dagger \&$ M. G. VANNUCCHI ${ }^{\star}$ \\ ${ }^{\star}$ Department of Anatomy, Histology and Forensic Medicine, Section of Histology, University of Florence, Viale G. Pieraccini 6, \\ Florence, Italy \\ $\dagger$ STEMBIO Department, Physiology Laboratory, University of Palermo, Viale delle Scienze, Palermo, Italy
}

\begin{abstract}
Background Glucagon-like peptide 2 (GLP-2), a nutrient-responsive hormone, exerts various actions in the gastrointestinal tract that are mediated by a G-protein coupled receptor called GLP-2R. A little information is available on GLP-2R expression in enteric neurons and nothing on the interstitial cells of Cajal (ICC). Methods We investigated presence and distribution of the GLP-2R in the mouse duodenum by immunohistochemistry and the potential motor effects of GLP-2 on the spontaneous and neurally evoked mechanical activity. Key Results The GLP-2R was expressed by the myenteric and submucosal neurons. Labelling was also present in nerve varicosities within the circular muscular layer and at the deep muscular plexus (DMP). No immunoreactive nerve fiber was seen within the longitudinal muscle layer. The GLP-2R-positive neurons were either excitatory (SP- and choline-acetyltransferase-positive) or inhibitory (vasoactive intestinal polypeptide and nNOS-positive). The ICC, both at the myenteric plexus and at the DMP, never expressed GLP$2 R$ but, especially those at the DMP, were surrounded by GLP-2R-positive nerve varicosities co-expressing either excitatory or inhibitory neurotransmitters. Quantitative analysis demonstrated a consistent prevalence of GLP-2R on the excitatory pathways. In agreement, the functional results showed that the administration of GLP-2 in vitro caused decrease of
\end{abstract}

Address for Correspondence

Prof. Maria Giuliana Vannucchi MD PhD, Department of Anatomy, Histology and Forensic Medicine, Section of Histology, University of Florence, Viale Pieraccini, 6, 50139 Florence, Italy.

Tel: +39 055 4271389; fax: +39055 4271385;

e-mail: mariagiuliana.vannucchi@unifi.it

Received: 14 February 2011

Accepted for publication: 13 June 2011 the spontaneous contractions mediated by nitric oxide release and reduction of the evoked cholinergic contractions. Conclusions \& Inferences The present findings indicate that the GLP-2R is expressed by inhibitory and excitatory neurons, the GLP-2 inhibits the muscle contractility likely decreasing cholinergic neurotransmission and increasing nitric oxide production, and this effect is possibly mediated by the ICC-DMP recruitment.

Keywords enteric neurons, excitatory neurotransmitters, glucagon-like hormones, immunohistochemistry, inhibitory neurotransmitters, intestinal motility.

\section{INTRODUCTION}

Glucagon- like peptide 2 (GLP-2), first recognized as an intestinal growth factor, ${ }^{1}$ is a 33 -amino-acid peptide mainly produced by the enteroendocrine L-cells located in the duodenum, distal small intestine, and colon. ${ }^{2,3}$ There are several evidences that GLP-2 inhibits gastrointestinal motility in laboratory mammals ${ }^{4-6}$ whereas results from human studies are conflicting. In fact, while Meier and co-workers ${ }^{7}$ showed that GLP-2 did not influence gastric emptying, another study demonstrated a dose-dependent increase in gastric emptying time after GLP-2 infusion compared to controls. ${ }^{8}$

The GLP-2 effects are due to the interaction with a specific receptor (GLP-2R) coupled to a G protein and belonging to the class $\mathrm{B}$ glucagon-secretin receptor family. ${ }^{9}$ GLP-2 binding to the transfected receptor caused an increase in adenosine $3^{\prime}, 5^{\prime}$-cyclic monophosphate (cAMP) consistent with findings from studies of related members of the glucagon/GLP-1R family. ${ }^{9,10}$ Furthermore, it has also been demonstrated that 
GLP-2R is coupled to different $G$ protein subunits and that it activates multiple signaling pathways. ${ }^{11,12}$

The presence of GLP-2R has been reported in the central nervous system and in the gastrointestinal tract. ${ }^{9,11,13-16}$ In particular, high levels of GLP-2R mRNA have been found in the jejunum, followed by duodenum, ileum, colon, and stomach ${ }^{9,17}$ and, by immunocytochemical techniques, GLP-2R expression was detected in subsets of human and mouse endocrine cells of the stomach, and small, ${ }^{16}$ and large intestine. ${ }^{15}$ Guan and co-workers ${ }^{18}$ detected GLP-2R-immunoreactivity (IR) in the enteroendocrine cells and myenteric neurons of porcine jejunum where it co-localized with serotonin in the former and with endothelial nitric oxide synthase (eNOS) and vasoactive intestinal polypeptide (VIP) in the latter. Furthermore, by using in situ hybridization and immunohistochemistry, GLP-2R was found on subepithelial myofibroblasts of rat, mouse, and human small and large intestine, ${ }^{19}$ and in the myenteric neurons of the mouse jejunum and colon. ${ }^{20}$ We recently showed the presence of GLP-2R-IR in neurons of myenteric and submucous plexus of mouse colon and demonstrated that more than $50 \%$ of the myenteric neurons shared the choline-acetyltransferase (ChAT)-IR. ${ }^{6}$ These results, together with the physiological ones, allowed us to conclude that the activation of GLP-2R located on cholinergic neurons modulated negatively the colonic spontaneous and electrically evoked contractions through inhibition of acetylcholine release. ${ }^{6}$

Information on the presence and cell localization of the GLP-2R in the duodenum is lacking. Therefore, we investigated, by immunohistochemistry, the cellular distribution of GLP-2R in the mouse duodenum and evaluated, by ChAT, SP, nNOS, and VIP co-labelling, whether the enteric neurons expressing the GLP-2R were excitatory, inhibitory or both. Besides, by using the c-kit labelling, we also investigated whether the interstitial cells of Cajal (ICC) express GLP-2R and/or were innervated by GLP-2R-IR nerve fibers. In parallel, the potential peripheral motor effects of GLP-2 on the spontaneous mechanical activity and on neurally evoked responses in mouse duodenum were examined

Results obtained would help in understanding the role of this receptor in one of the intestinal regions richer in L-enteroendocrine cells and that it plays important roles in the digestion and absorption processes.

\section{MATERIALS AND METHODS}

\section{Animals and specimens collection}

The experiments were authorized by Ministero della Sanità (Rome, Italy), following the guidelines of the European Commu- nities Council Directive of 24 November 1986. Ten adult male mice weighing $25 \pm 1.5 \mathrm{~g}$ (C57BL/10, Harlan, Udine, Italy) were fed ad libitum prior to use and then killed by cervical dislocation. The abdomen was immediately opened and the duodenum was removed from a position just distal to the pylorus. The content of the excised segments was cleaned with $0.9 \% \mathrm{NaCl}$ solution and segments of about $2 \mathrm{~cm}$ in length were cut.

\section{Immunohistochemistry}

For the morphological experiments (four animals), the specimens were fixed in $4 \%$ paraformaldehyde for $4 \mathrm{~h}$ at $4{ }^{\circ} \mathrm{C}$. The specimens were cryoprotected in $30 \%$ sucrose in phosphate-buffered saline (PBS) for approximately $12 \mathrm{~h}$ at $4{ }^{\circ} \mathrm{C}$ and then frozen in Killik cryostat-embedding medium (Bio-Optica, Milan, Italy) Transverse cryosections, $8 \mu \mathrm{m}$ thick, were cut and collected on polylysinecoated slides and then stored at $-20{ }^{\circ} \mathrm{C}$. The slices were preincubated in $0.5 \%$ Triton (Sigma Aldrich, Milan, Italy) and 1.5\% bovine serum albumin (BSA) (Sigma Aldrich, Milan, Italy) in PBS for $15 \mathrm{~min}$ at room temperature. And then the sections were incubated with primary antibody diluted in $0.5 \%$ Triton and $1.5 \%$ BSA in PBS for $24 \mathrm{~h}$ at $4{ }^{\circ} \mathrm{C}$ and successively with secondary antibody diluted in $0.5 \%$ Triton and $1.5 \%$ BSA in PBS for $2 \mathrm{~h}$ at room temperature.

The GLP-2R antibody presently used recognizes the epitope mapping within an N-terminal extracellular domain of GLP-2R of human origin. Double labelling for GLP-2R/nNOS, GLP-2R/SP, GLP-2R/c-kit, SP/nNOS, ChAT/SP, nNOS/ChAT, and nNOS/VIP was performed as follows: after the first incubation as described above, the sections were incubated again with another primary antibody and with the specific secondary antibody. The double labelling of GLP-2R with ChAT or with VIP gave unpredictable results since there was a complete and unreliable overlapping in some sections, while in others it did not. For this reason, we decided to made the following experiments: transverse sequential sections, $4 \mu \mathrm{m}$ thick, were cryocut from each specimen and collected on slides (four sections/slide; two slides/specimen) in two separate areas, one area containing the first and the third section, the other area containing the second and the fourth section. Serial sections were placed on different slides. Each area was bordered with a Pap Pen and the two sections of one area were incubated with GLP-2R antibody as described above while the two sections of the neighbor area were incubated with ChAT polyclonal antibody (a generous gift of Dr. M. Schemann who characterized this antibody, ${ }^{21}$ at final dilution of $1: 500$ overnight at $4{ }^{\circ} \mathrm{C}$, or with VIP polyclonal antibody (Affinity Research Products Limited, Nottingham, UK) at final dilution of $1: 300$ for $24 \mathrm{~h}$ at $4{ }^{\circ} \mathrm{C}$. The two immunoreactions were revealed with the secondary antibodies Alexa Fluor 488 Donkey anti Goat and the Alexa Fluor 568 Goat anti Rabbit (Invitrogen, San Diego, CA, USA) $1: 333$, respectively, for $2 \mathrm{~h}$ at room temperature.

The antibodies details are reported in Table 1.

\section{Specificity tests}

For all the antibodies, negative controls were performed by omitting the primary antibody or substituting it with a nonimmune rabbit, rat or mouse serum. For the monoclonal nNOS antibody the sections were pretreated for $15 \mathrm{~min}$ with unlabelled goat anti-mouse whole IgG molecule (Sigma, St.Louis, MO, USA). To evaluate the specificity of the polyclonal GLP-2R antibody, the staining was checked by pre-adsorption with its blocking peptide (Santa Cruz Biotechnology, CA, USA). A mixture of GLP-2R primary antibody, at working dilution, was combined with a fivefold by weight excess of blocking peptide in a small volume of 
Table 1 Primary and secondary antibodies used

\begin{tabular}{|c|c|c|}
\hline & Company & Dilution \\
\hline \multicolumn{3}{|l|}{ Primary antibodies } \\
\hline GLP-2R goat polyclonal & $\begin{array}{l}\text { Santa Cruz Biotechnology, } \\
\text { Santa Cruz, CA, USA }\end{array}$ & $1: 100$ \\
\hline c-kit rabbit polyclonal & $\begin{array}{l}\text { Calbiochem, San Diego, } \\
\text { CA, USA }\end{array}$ & $1: 100$ \\
\hline nNOS rabbit polyclonal & $\begin{array}{l}\text { Chemicon Millipore } \\
\text { Corporation, Billerica, } \\
\text { MA, USA }\end{array}$ & $1: 1000$ \\
\hline $\begin{array}{l}\text { nNOS mouse } \\
\text { monoclonal }\end{array}$ & $\begin{array}{l}\text { BD Bioscience, Franklin } \\
\text { Lakes, NJ, USA }\end{array}$ & $1: 200$ \\
\hline SP rat monoclonal & $\begin{array}{l}\text { Santa Cruz Biotechnology, } \\
\text { Santa Cruz, CA, USA }\end{array}$ & $1: 50$ \\
\hline VIP rabbit polyclonal & $\begin{array}{l}\text { Affinity Research Products, } \\
\text { Nottingham. UK }\end{array}$ & $1: 300$ \\
\hline \multicolumn{3}{|l|}{ Secondary antibodies } \\
\hline $\begin{array}{l}\text { Alexa Fluor } 488 \\
\text { Donkey anti Goat }\end{array}$ & $\begin{array}{l}\text { Invitrogen, San Diego, } \\
\text { CA, USA }\end{array}$ & $1: 333$ \\
\hline $\begin{array}{l}\text { Alexa Fluor } 488 / 568 \\
\text { Goat anti Rabbit }\end{array}$ & $\begin{array}{l}\text { Invitrogen, San Diego, } \\
\text { CA, USA }\end{array}$ & $1: 333$ \\
\hline $\begin{array}{l}\text { Alexa Fluor } 488 / 568 \\
\text { Goat anti-Mouse }\end{array}$ & $\begin{array}{l}\text { Invitrogen, San Diego, } \\
\text { CA, USA }\end{array}$ & $1: 333$ \\
\hline $\begin{array}{l}\text { Alexa Fluor } 568 \\
\text { Goat anti Rat }\end{array}$ & $\begin{array}{l}\text { Invitrogen, San Diego, } \\
\text { CA, USA }\end{array}$ & $1: 333$ \\
\hline
\end{tabular}

GLP-2R, glucagon-like peptide 2 receptor; VIP, vasoactive intestinal polypeptide.

phosphate buffer. This mixture was incubated overnight at $4{ }^{\circ} \mathrm{C}$; then, centrifuged at $2000 \mathrm{~g}$ for $10 \mathrm{~min}$. A small volume of supernatant was used instead of the primary antibody in a usual immunohistochemistry experimental procedure (Fig. 1D).

\section{Quantitative analysis}

The GLP-2R-IR neurons as well GLP-2R/nNOS, GLP-2R/SP, ChAT/SP, nNOS/VIP, nNOS/ChAT, and nNOS/SP double labelled neurons were counted on three sections cut at a distance of $50 \mu \mathrm{m}$ from each other, taken from the duodenum of three control mice. Quantification of the neurons sharing GLP-2R-IR and ChAT-IR or VIP-IR was done on the sequential sections collected as described above. Digitized images of the entire perimeter of the muscle wall were acquired using at $\mathrm{x} 40$ objective. Field edges were defined based on structural details within the tissue section to ensure that the fields did not overlap. Comparison between pictures taken from GLP-2R-IR sections, from ChAT-IR, and from VIP-IR sections at the same level was done to identify and quantify those neurons that shared two markers. All the counts were done by two of us blind to each others' results on a total of 12 sections for each antibody. The results were expressed as mean \pm SE of the number of neurons per $6 \mathrm{~mm}$, i.e., the perimeter of each section.

\section{Physiology}

For functional experiments, preparations were mounted in a custom-designed horizontal organ bath (volume $=5 \mathrm{~mL}$ ), which was continuously perfused with oxygenated $195 \% \mathrm{O}_{2}$ and $5 \%$ $\left.\mathrm{CO}_{2}\right)$ and heated $\left(37^{\circ} \mathrm{C}\right)$ Krebs solution with the following composition $\left(\mathrm{mmol} \mathrm{L}^{-1}\right): \mathrm{NaCl} \mathrm{119;} \mathrm{KCl} 4.5 ; \mathrm{MgSO}_{4} 2.5 ; \mathrm{NaHCO}_{3}$ $25 ; \mathrm{KH}_{2} \mathrm{PO}_{4} 1.2 ; \mathrm{CaCl}_{2} 2.5 ;$ glucose 11.1. The mechanical activity was recorded as previously described. ${ }^{22}$ Briefly, distal end of duodenal segment was tied around the mouth of a J-tube, which was connected via a $\mathrm{T}$ catheter to a pressure transducer (Statham Mod. P23XL; Grass Medical Instruments, Quincy, MA, USA) and to a syringe for filling the preparation with Krebs solution. The legated proximal end was secured with a silk thread to an isometric force transducer (Grass FT03; Grass Instruments Co., Quincy, MA, USA). Preparations were filled with $0.1 \mathrm{~mL}$ Krebs solution and subjected to an initial tension of $0.1 \mathrm{~g}$. Mechanical signals were detected as changes in both endoluminal pressure and isometric tension, which reflect the activity of circular and longitudinal muscle, respectively, ${ }^{6,23}$ and recorded on an ink writer polygraph (Grass model 7D; Grass Instruments Co., Quincy, MA, USA). Preparations were allowed to equilibrate for about $60 \mathrm{~min}$ before starting the experiment. After the equilibration time, increasing concentrations of GLP-2 $\left(1-100 \mathrm{nmol} \mathrm{L}^{-1}\right)$ were added non-cumulatively to the bath at and the effects on the baseline tone and amplitude of phasic contractions were examined over a period of $10 \mathrm{~min}$. The interval between single concentrations was $40 \mathrm{~min}$ to avoid tachyphylaxis.

In another set of preparations, the influence of GLP-2 (1-100 $\mathrm{nmol} \mathrm{L}{ }^{-1}$ ) on the electrically evoked responses was evaluated in the circular muscle. Electrical field stimulation (EFS) was supplied by an S88 square-wave pulse generator (Grass Medical Instruments, Quincy, MA, USA) and applied through a pair of platinum plates, placed in parallel on either sides of the intestinal segment. Trains of stimuli (duration $5 \mathrm{~s}$, supramaximal voltage, $8 \mathrm{~Hz}$ and $0.5 \mathrm{~ms}$ pulse duration) were applied to duodenal preparations at intervals of $70 \mathrm{~s}$. Preliminary experiments were performed to assess the neurotransmitters involved in the responses. Under basal condition, EFS induced a muscular contraction, which was abolished by atropine $\left(1 \mu \mathrm{mol} \mathrm{L}{ }^{-1}\right)$, suggesting its cholinergic origin. To study non-cholinergic non adrenergic (NANC) responses, atropine $\left(1 \mu \mathrm{mol} \mathrm{L}^{-1}\right)$ and guanethidine $\left(1 \mu \mathrm{mol} \mathrm{L}^{-1}\right)$ were added to Krebs solution at the beginning of experiment. In NANC conditions EFS induced a transient relaxation followed by a NANC contraction. The relaxation was abolished by L-NAME $\left(300 \mu \mathrm{mol} \mathrm{L}^{-1}\right)$, suggesting that it was mediated by nitric oxide. The contraction was abolished by coadministration of SR140333 $\left(0.1 \mu \mathrm{mol} \mathrm{L}^{-1}\right)$ and SR48968 $\left(0.1 \mu \mathrm{mol} \mathrm{L}^{-1}\right)$, NK1 and NK2 receptor antagonists, suggesting its tachykinergic origin. All electrically evoked responses were abolished by tetrodotoxin (TTX; $1 \mu \mathrm{mol} \mathrm{L}{ }^{-1}$ ), suggesting their neural origin.

Increasing concentrations of GLP-2 (1-100 nmol L-1) were left in contact with the preparations for $7 \mathrm{~min}$.

Data analysis and statistical tests The mean amplitude of the spontaneous pressure waves was determined for $7 \mathrm{~min}$ before and after GLP-2 administration. The changes in the mean amplitude of the pressure waves induced by GLP-2 were expressed as percentages of the values obtained before GLP-2 addition to the bath. The amplitude of the evoked-contractile response was measured as the difference between the minimum of baseline activity and the highest contraction following the EFS. Likewise the GLP-2 effects on the electrically evoked responses were expressed as a percentage of the response produced by EFS in control conditions. All data are expressed as mean values \pm SEM. The letter $n$ indicates the number of experimental animals. Statistical analysis was performed by means of ANOVA, followed by Bonferroni's post hoc test. A probability value of less than 0.05 was regarded as significant.

Drugs The following drugs were used: atropine sulfate, guanethidine monosulfate, $N_{\omega}$-nitro-L-arginine methyl ester (L-NAME), tetrodotoxin (TTX) (Sigma-RBI, Milano, Italy), glucagon-like peptide-2 (Tocris-Bioscience, Bristol, UK), ((S)1-\{2-[3-(3,4-dichlorophenyl)-1-(3-isopropoxy-phenylacetyl)- $\quad$ piperidin-3-yl]ethyl\}-4- 

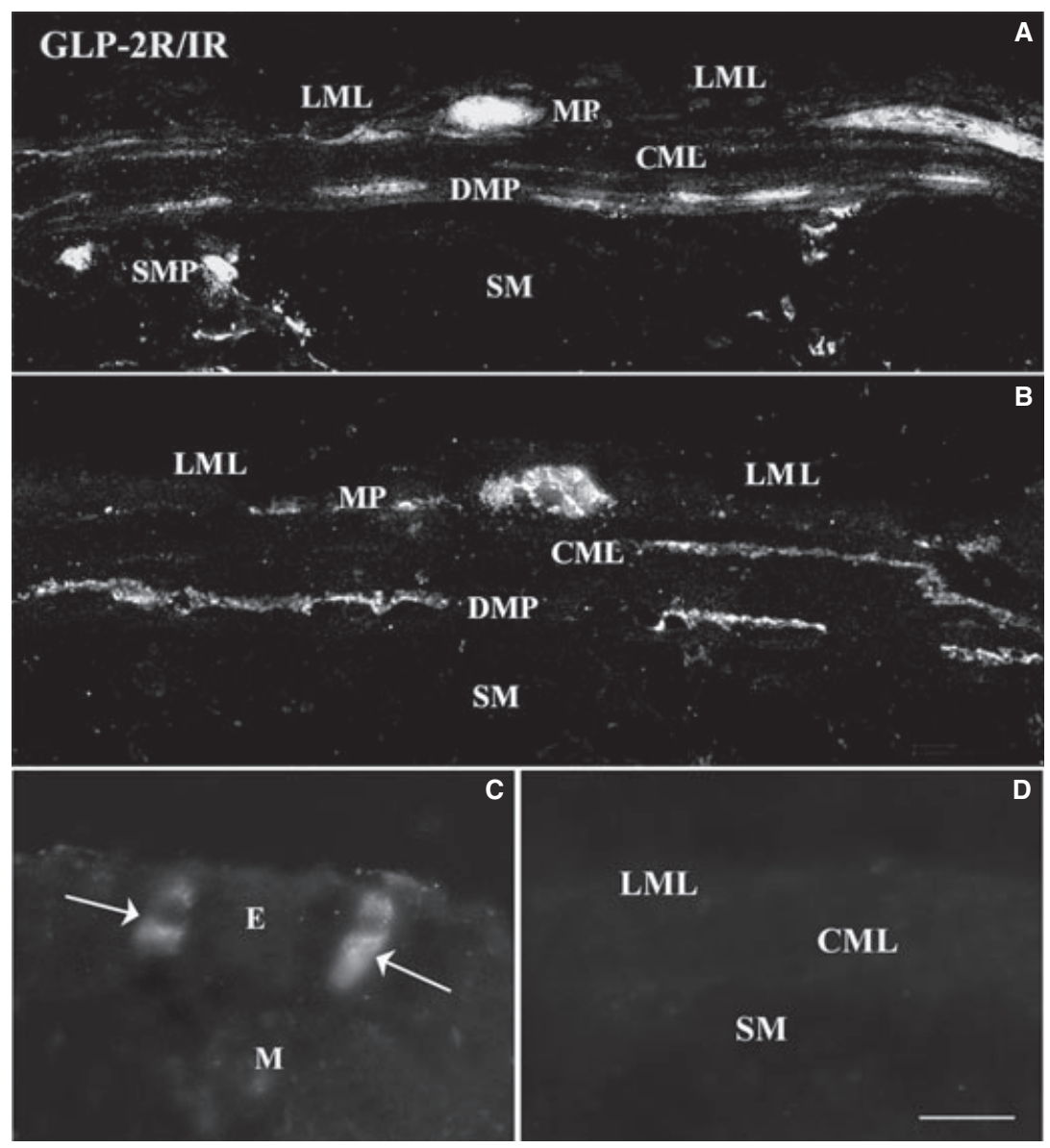

Figure 1 (A and B) GLP-2R distribution. In both myenteric (MP) and submucous (SMP) neurons the labelling is diffuse throughout the perikaryon and has a granular aspect. Varicose nerve fibers are present at the MP, within the circular muscle layer (CML) and at the deep muscular plexus (DMP). No immunoreactive nerve fibers are present within the longitudinal muscle layer (LML). In B, some of the positive DMP nerve endings encircle thin, spindle-shaped negative cells. (C) Two GLP-2R-IR enteroendocrine cells (arrows) in the lining epithelium (E). (D) undetectable GLP-2R-IR after preadsorption with blocking peptide. $\mathrm{SM}=$ submucosa $. \mathrm{M}=$ mucosa Scale Bar: A-B-D $=30 \mu \mathrm{m}, \mathbf{C}=10 \mu \mathrm{m}$. phenyl-1-azoniabicyclo[2.2.2]octane, chloride) (SR140333) and ((S)$\mathrm{N}$-methyl-N[4-(4-acetylamino-4-phenylpiperi-dino)-2-(3,4-dichlorophenyl)butyl]benzamide (SR48968) (Sanofi Recherche, Montpellier Cedex, France). Each compound was prepared as a stock solution in distilled water. And SR48968 and SR140333 were dissolved in dimethylsulphoxide (DMSO), which had no effect on the tissue. The working solutions were prepared fresh the day of the experiment by diluting the stock solutions in Krebs.

\section{RESULTS}

\section{Immunohistochemistry}

GLP-2R distribution Both myenteric and submucous neurons expressed GLP-2R-IR (Fig. 1A,B). The labelling was diffuse throughout the perikaryon and had a granular aspect. Besides, several nerve fibers and endings inside the ganglia were labelled and some of them surrounded GLP-2R negative neurons. The GLP-2R-IR fibers were also detected in the circular muscle layer (Fig. 1A,B) and most of them were located at the deep muscular plexus, DMP, (Fig. 1A,B). In the latter region some of the positive nerve endings encircled thin, spindle-shaped negative cells (Fig. 1B). No immunoreactive nerve fiber was seen within the longitudinal muscle layer (Fig. 1A,B). As expected, GLP-2R-IR was detected in some of the glandular cells located in the epithelium and likely corresponding to the enteroendocrine ones (Fig. 1C).

Quantitative analysis demonstrated that the number of GLP-2R-IR neurons/slice was $28.38 \pm 0.8$ in the myenteric plexus $(\mathrm{MP})$ and $1.4 \pm 0.3$ in the submucosal plexus (SMP). Quantitative data are reported in detail in the Table 2.

GLP-2R/c-kit double labelling The interstitial cells of Cajal identified by c-kit-IR, both at the myenteric plexus (ICC-MP) and at the deep muscular plexus (ICC-DMP), never expressed GLP-2R-IR (Fig. 2A). However, both of them were closely contacted by GLP-2R-IR nerve varicosities (Fig. 2A) which frequently co-expressed ChAT-IR, VIP-IR, nNOS-IR or SP-IR (see below).

GLP-2R and neurotransmitter co-localizations At the myenteric plexus, GLP-2R-IR was expressed by either inhibitory (nNOS- and VIP-IR) (Fig. 2B and Fig. 2E,F, respectively) or excitatory (SP- and ChAT-IR) 
Table 2 Mean number of GLP-2R-IR neurons/slice at the myenteric and submucous plexuses, and percentage of those co-expressing nNOS, VIP, $\mathrm{ChAT}$ and SP. The slice measured $6 \mathrm{~mm}$ in perimeter

\begin{tabular}{|c|c|c|c|c|c|}
\hline Plexus & $\begin{array}{l}\text { Numbers } \\
\text { of the } \\
\text { GLP-2R-IR } \\
\text { neurons }\end{array}$ & $\begin{array}{l}\% \text { of those } \\
\text { co-expressing } \\
\text { nNOS-IR }\end{array}$ & $\begin{array}{l}\% \text { of those } \\
\text { co-expressing } \\
\text { VIP-IR }\end{array}$ & $\begin{array}{l}\% \text { of those } \\
\text { co-expressing } \\
\text { ChAT-IR }\end{array}$ & $\begin{array}{l}\% \text { of those } \\
\text { co-expressing } \\
\text { SP-IR }\end{array}$ \\
\hline $\mathrm{MP}$ & $28.4 \pm 0.8$ & $17.9 \pm 2.0 \%$ & $10.3 \pm 1.5 \%$ & $71.3 \pm 5.8 \%$ & $27.0 \pm 1.4 \%$ \\
\hline SMP & $1.4 \pm 0.3$ & 0 & 0 & 0 & $100 \%$ \\
\hline
\end{tabular}

GLP-2R-IR, glucagon-like peptide 2 receptor immunoreactivity; VIP-IR, vasoactive intestinal polypeptide immunoreactivity; chAT-IR, choline-acetyltransferase immunoreactivity.

Figure 2 (A) GLP-2R/c-kit double labelling. The interstitial cells of Cajal (in red), both at the myenteric plexus (MP) and at the deep muscular plexus (DMP), are GLP-2R negative, but contacted by many GLP-2R-IR nerve varicosities (in green). (B) GLP-2R/ nNOS double labelling. At the myenteric and submucous plexus (SMP) some neurons (in yellow) co-express GLP-2R-IR (in green) and nNOS-IR (in red). The same double labelling is present in many intragangliar and intramuscular nerve fibers, especially at the deep muscular plexus. The arrow indicates one myenteric nNOS-IR (in red) neuron contacted by GLP-2R-IR (in green) nerve endings. (C and D) GLP-2R/SP double labelling. At the MP, two neurons (in yellow) co-express GLP-2R-IR (in green) and SP-IR (in red). The same double labelling is present in the nerve fibers of the DMP that surround negative spindle-shaped cells. In (D) two submucous neurons, one double labelled (in yellow) and one (in green) GLP-2R positive only. (E and F) GLP-2R and VIP labelling. Serial sections. At the MP, one (1) of the two GLP-2R-IR neurons is also VIP-IR (1). In F, One ICC at the DMP is surrounded by many VIP-IR nerve endings. (G and H) GLP-2R and ChAT labelling. Serial sections. At the MP three $(1,2,3)$ of the GLP-2R-IR neurons are also ChAT-positive $(1,2,3) . \mathrm{SM}=$ sub mucosa. Scale Bar: $30 \mu \mathrm{m}$.
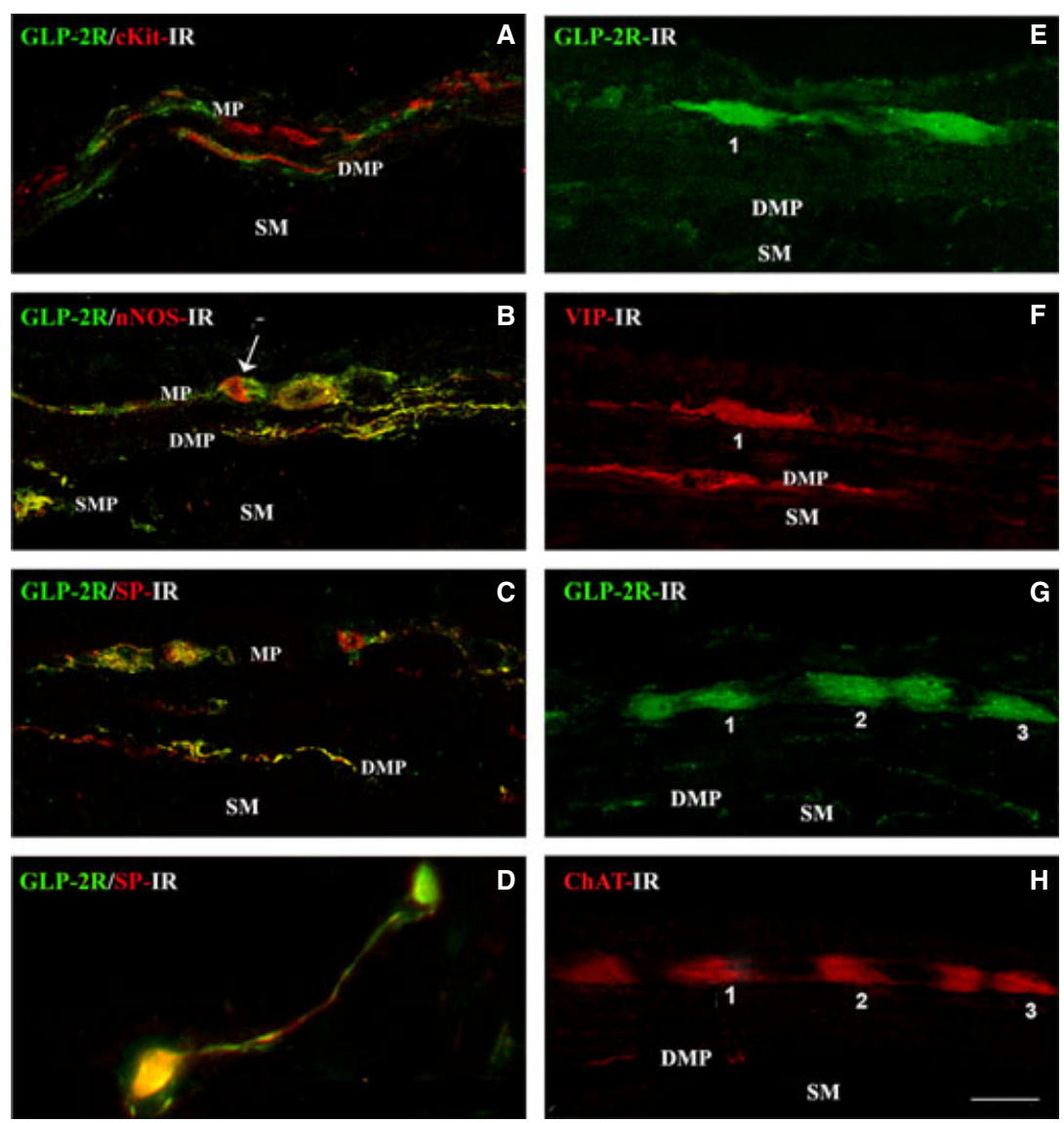

(Fig. 2C,D and Fig. 2G,H, respectively) neurons. In addition, some of the nNOS-IR and SP-IR myenteric neurons were contacted by GLP-2R-IR nerve endings (Fig. 2B,C). At the SMP, only the SP-IR neurons co-expressed GLP-2R (Fig. 2D). For details about the number of neurons and the percentage of co-localizations see Table 2 .

Neurotransmitters double labelling Several of the ChAT-IR myenteric neurons shared SP-IR (Fig. 3A), while in the SMP the two markers did not co-localized. At the DMP (Fig. 3A) the two neurotransmitters co-localized and the nerve endings closely contacting negative cells (presumably, the ICC-DMP). None of the ChAT-IR neurons, either at the MP or at the SMP (Fig. 3B), co-expressed nNOS-IR. Many of the SP-IR neurons were surrounded by nNOS-IR nerve endings at both plexuses, but the two stainings never co-localized (Fig. 3C). In the myenteric plexus some of the VIP-IR neurons shared nNOS-IR (Fig. 3D), while in the submucous plexus these two markers did not co-localize. Many of the DMP nerve fibers were nNOS/VIP-IR (Fig. 3D) and in contact with the ICC-DMP (Fig. 3E).

For details about the number of the ChAT-, SP-, nNOS-, and VIP-IR neurons and the percentage of those sharing neurotransmitters co-localizations see Table 3. 

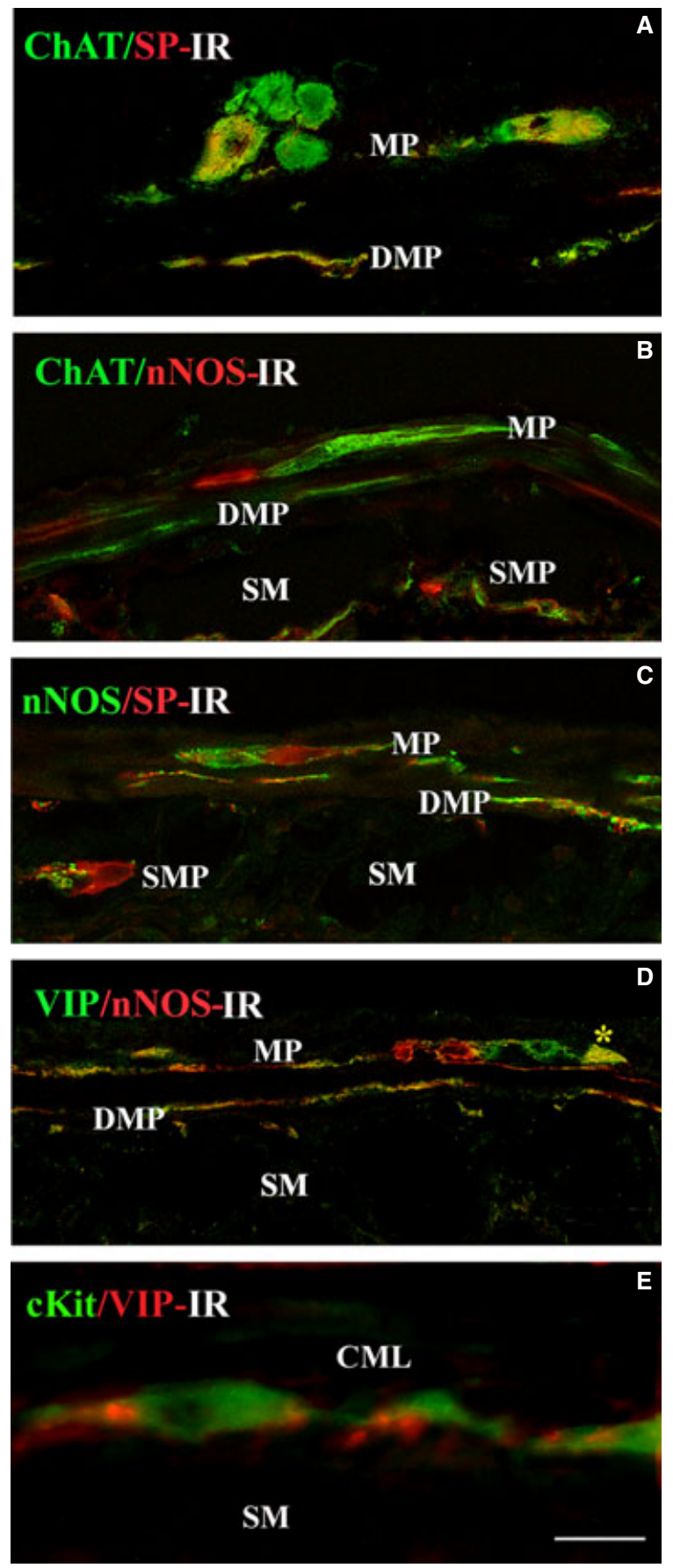

Figure 3 (A) Two of the 5 ChAT-IR myenteric neurons share SP-IR. At the deep muscular plexus (DMP) the two markers co-localize and the nerve endings surround negative cells (presumably the interstitial cells of Cajal, ICC). (B) Neither the ChAT-IR neurons, either at the myenteric plexus (MP) or at the submucous plexus (SMP), nor the ChAT-IR nerve endings co-express nNOS-IR. (C) The SP-IR neurons are surrounded by nNOS-IR nerve endings at both plexuses but the two staining never co-localize. (D) In the MP one of the VIP-IR neurons (asterisk) shares nNOS-IR. Many of the DMP nerve fibers are nNOS/VIP-IR. (E) Numerous VIP-IR nerve endings (in red) are in contact with the ICC-DMP (in green). SM = submucosa, $\mathrm{CML}=$ circular muscle layer. Scale Bar: A-D $=30 \mu \mathrm{m}, \mathrm{E}=10 \mu \mathrm{m}$.

\section{Functional study}

Effects of GLP-2 on spontaneous mechanical activity As previously described, ${ }^{20}$ mouse duodenum exhibited spontaneous mechanical activity characterized by phasic changes in both endoluminal pressure $\left(1.5 \pm 0.2 \mathrm{~cm} \mathrm{H} \mathrm{H}_{2} \mathrm{O}, n=6\right)$ and isometric tension $(175 \pm 30 \mathrm{mg} ; n=6)$. GLP-2 $\left(1-100 \mathrm{nmol} \mathrm{L}^{-1}\right)$ caused a concentration-dependent inhibitory effect, characterized by a decrease of the spontaneous contraction amplitude (Fig. 4) and a slight reduction of the basal tone in the circular muscle, without affecting the spontaneous mechanical activity of duodenal longitudinal muscle (amplitude $170 \pm 25 \mathrm{mg} ; n=6 P>0.05$ ). The GLP-2-induced inhibitory effects were not observed in the presence of TTX $\left(1 \mu \mathrm{mol} \mathrm{L}^{-1}\right)$ or L-NAME $\left(300 \mu \mathrm{mol} \mathrm{L}^{-1}\right)$, (Fig. 4).

Effects of GLP-2 on the neurally evoked mechanical responses In normal Krebs, EFS (trains of $8 \mathrm{~Hz}$ for $5 \mathrm{~s}$ ) induced cholinergic contractions in the circular muscle $\left(2.6 \pm 0.5 \mathrm{~cm} \mathrm{H}_{2} \mathrm{O} ; n=6\right)$, which were reduced by GLP-2 $\left(1-100 \mathrm{nmol} \mathrm{L}^{-1}\right)$ in a concentration-dependent manner (Fig. 5A). The GLP-2 at the maximal concentration tested $\left.(0.1 \mu \mathrm{mol} \mathrm{L})^{-1}\right)$ produced about $60 \%$ of reduction of the evoked contraction amplitude (Fig. 5A).

In the presence of atropine $\left(1 \mu \mathrm{mol} \mathrm{L}^{-1}\right)$ and guanetidine $\left(1 \mu \mathrm{mol} \mathrm{L}^{-1}\right)$, EFS produced a transient nitrergic relaxation of circular muscle $\left(1.1 \pm 0.4 \mathrm{~cm} \mathrm{H}_{2} \mathrm{O} ; n=6\right)$, followed by NANC contraction. $\left(2.8 \pm 0.6 \mathrm{~cm} \mathrm{H}_{2} \mathrm{O}\right.$; $n=6)$. GLP-2 $\left(1-100 \mathrm{nmol} \mathrm{L}^{-1}\right)$ induced a concentration-dependent increase of the relaxation amplitude without affecting the NANC contraction (Fig. 5B).

\section{DISCUSSION}

The present immunohistochemical findings demonstrated that in the mouse duodenum the neuronal cells expressed the GLP-2R. The receptor was distributed in the myenteric and submucous neurons and in several nerve varicosities which were particularly abundant at the DMP. Interestingly, about $30 \%$ of the GLP-2R-IR neurons shared inhibitory neurotransmitters while up to $70 \%$ were excitatory neurons. Finally, the GLP-2RIR nerve varicosities, surrounding the ICC at the MP and at the DMP, co-expressed either inhibitory or excitatory neurotransmitters. No GLP-2R-IR varicosity was observed in the longitudinal muscle layer. Physiological results demonstrated the ability of the GLP-2 to inhibit smooth muscle contraction by acting on both excitatory cholinergic pathways and inhibitory nitrergic pathways. 
Table 3 Mean number of myenteric neurons/slice expressing nNOS, VIP, ChAT and SP and percentage of those co-expressing these molecules and GLP-2R. The slice measured $6 \mathrm{~mm}$ in perimeter

\begin{tabular}{lcccc}
\hline & nNOS-IR & VIP-IR & ChAT-IR & SP-IR \\
\hline Number of neurons & $18.3 \pm 1.4$ & $10.0 \pm 1.0$ & $34.2 \pm 2.2$ & $17.0 \pm 0.9$ \\
$\%$ of co-expressing GLP-2R-IR & $27.3 \pm 3.1 \%$ & $34.8 \pm 1.5 \%$ & $51.9 \pm 4.2 \%$ & $47.8 \pm 3.4 \%$ \\
$\%$ co-expressing nNOS-IR & - & $65.7 \pm 3.4 \%$ & 0 & 0 \\
$\%$ co-expressing VIP-IR & $29.3 \pm 1.4 \%$ & - & 0 & 0 \\
$\%$ co-expressing ChAT-IR & 0 & 0 & - & $-34.5 \pm 1.5 \%$ \\
$\%$ co-expressing SP-IR & 0 & 0 & $37.3 \pm 1.7 \%$ & - \\
\hline
\end{tabular}

GLP-2R-IR, glucagon-like peptide 2 receptor immunoreactivity; VIP-IR, vasoactive intestinal polypeptide immunoreactivity; chAT-IR, cholineacetyltransferase immunoreactivity.

Figure 4 (A) Original tracings showing the effects of GLP-2 increasing concentrations on the mechanical spontaneous activity of the mouse duodenal circular muscle and the absence of any influence in the presence of L-NAME. Dotted line indicates the tone of the preparation. (B) Concentration-response curves for the inhibitory effects induced by GLP-2 on the spontaneous contraction amplitude before and after treatment of the preparations with TTX $\left(1 \mu \mathrm{mol} \mathrm{L}^{-1}\right)$ or L-NAME $\left(300 \mu \mathrm{mol} \mathrm{L}^{-1}\right)$. Data are expressed as a percentage of the resting contraction amplitude. (C) Concentration-response curves for the inhibitory effects induced by GLP-2 on the mechanical tone, which was taken to be the difference between the pressures observed before GLP-2 addition to the bath and the new stable level reached in the presence of each concentration of the peptide. Each value is the mean \pm SEM from 6 animals. ${ }^{\star} P<0.05$.

\section{A}

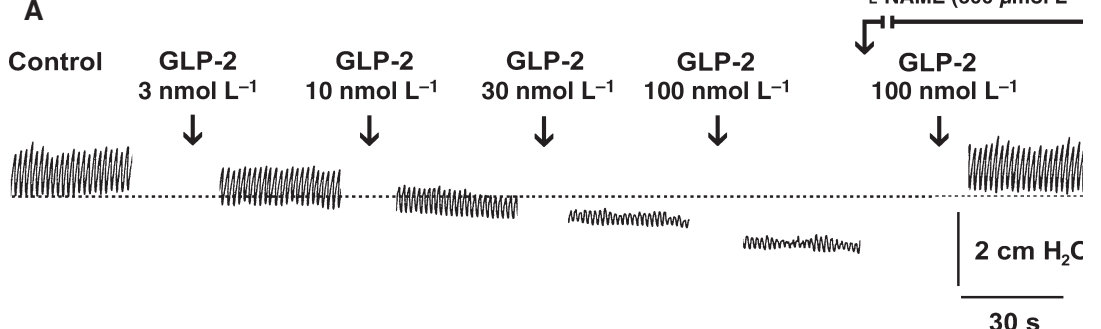

B

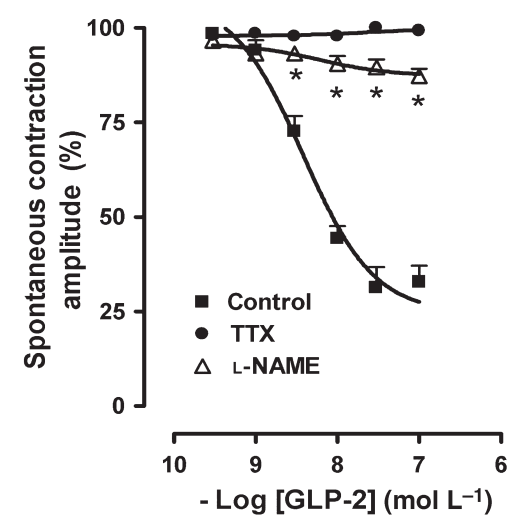

C

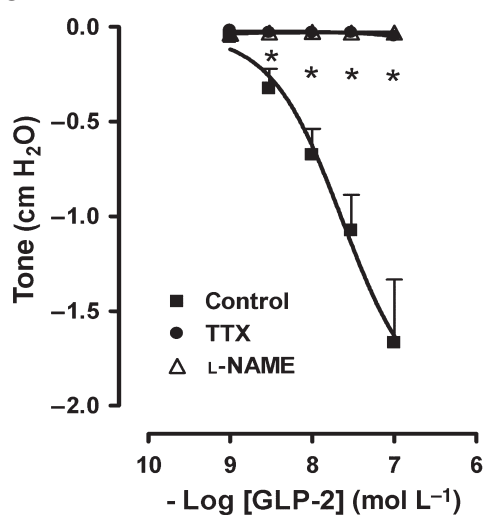

In a previous article we showed that in the mouse colon more than $50 \%$ of the GLP-2R-IR myenteric neurons were ChAT-positive and, in agreement with the physiological results, we concluded that the inhibitory action of the GLP-2 was due to a decrease of acetylcholine release. ${ }^{6}$ On the basis of the present data, the ability of the GLP-2 to inhibit duodenum motility should be the result of more complex interactions since the GLP-2R-IR is practically detected on all types of neurons. Moreover, the functional findings showing that the administration of GLP-2 in vitro involved either the nitrergic or the cholinergic pathways suggest that the inhibition of the gastrointestinal motor activity due to this peptide is the final result of a double and likely opposite effect on the inhibitory and excitatory neurons.
Co-localization experiments showed that up to $70 \%$ of the GLP-2R-IR neurons shared ChAT-IR, therefore the reduction in the evoked responses presently found are likely imputable to the inhibition of Ach release, similar to that observed in the mouse colon. ${ }^{6}$ Interestingly, although the great majority of SP-IR neurons co-expressed ChAT-IR, physiological results indicated that the tachykinin-induced contractions were not modified by the GLP-2 administration. This result would suggest that those neurons sharing ChAT- and GLP-2R-IR (the $52 \%$ out of the total cholinergic neurons) represent a distinct population in respect to those sharing ChAT- and SP-IR (the $37 \%$ out of the total cholinergic neurons). However, since $47 \%$ out of the SP-positive neurons were GLP-2R-IR and almost $85 \%$ of them were ChAT-positive it is very likely that 

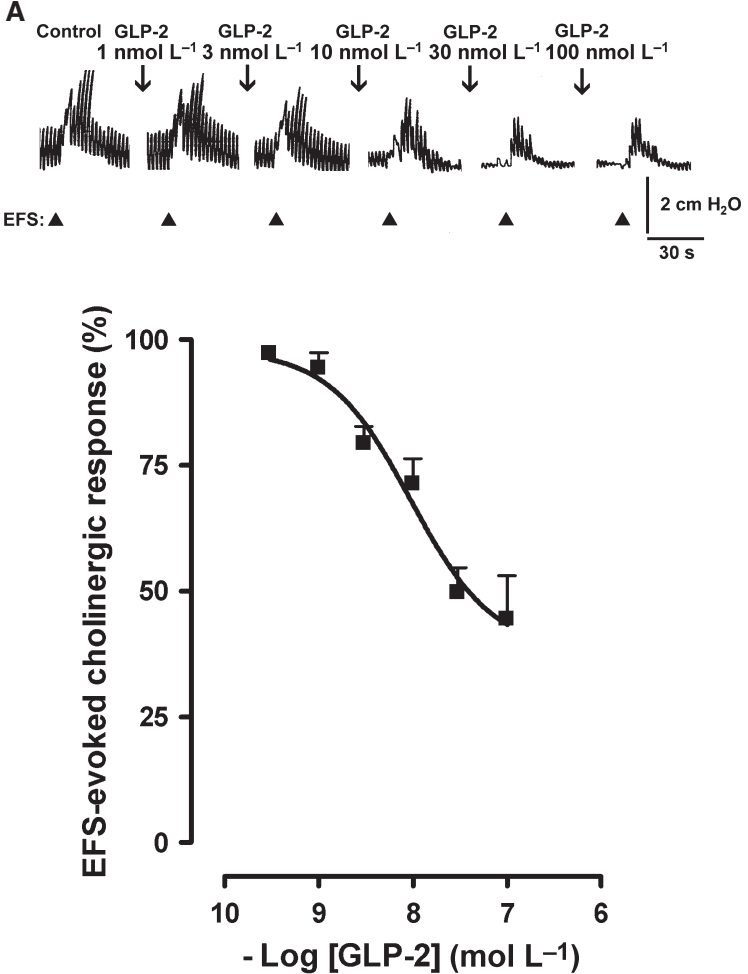

B
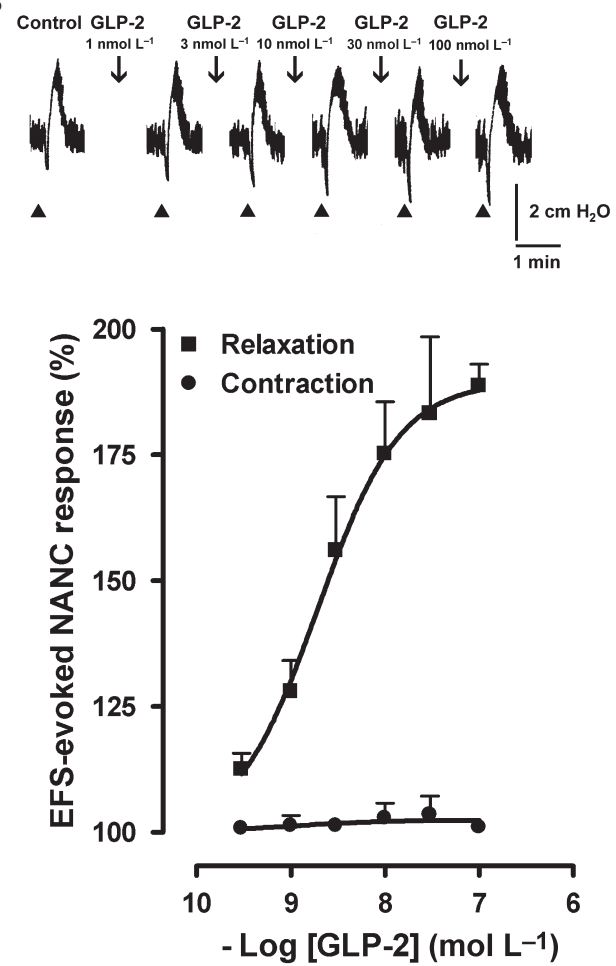

Figure 5 Effects induced by GLP-2 increasing concentrations on the cholinergic contractions (A) or on NANC nitrergic relaxations and tachychininergic contractions (B) in the circular muscle of mouse duodenum. Mechanical responses were evoked by EFS (train of 5 s, 0.5 ms, supramaximal voltage, $8 \mathrm{~Hz}$ ). Upper panel shows typical tracings and lower panel shows concentration-response curves. Data are expressed as a percentage of the response obtained in the absence of GLP-2, considered $100 \%$. Each value is mean \pm SEM from six animals.

SP-IR neurons that express GLP-2R represent part of the GLP-2R/ChAT-IR. Therefore, on the basis of both physiological and morphological results, we consider that the interaction between the GLP-2 and its receptor on the excitatory neurons selectively affects the cholinergic neurotransmission without involving the tachykinergic one. The possibility to differentially regulate the release of these two neurotransmitters from the same excitatory neuron was already reported. ${ }^{24,25}$

We also presently showed that almost $20 \%$ of the GLP-2R-IR neurons co-expressed nNOS while up to $27 \%$ out of the total nNOS-IR neurons shared the GLP2R-IR. The double labelling was detected either in the soma or in the nerve endings located in the circular muscle layer and, most of all, at the DMP. Comparing these results with those obtained for the GLP-1R-IR distribution in the mouse duodenum, ${ }^{22}$ similarities but also significant differences emerge. Indeed, while the co-expression of GLP-1R and nNOS was detected within the myenteric plexus only, ${ }^{22}$ the GLP-2R/nNOS co-labelling is also extended to nerve varicosities located in the circular muscle layer and DMP. These observations suggest that the GLP-1R is mainly located on myenteric interneurons while GLP-2R is also expressed by inhibitory motor neurons. The finding that the majority of the GLP-2R-IR is detected on cholinergic neurons (present data), while almost no GLP-1R labelling was seen on this neuron type, ${ }^{20}$ is in line with a different localization of these two receptors. Moreover, on the basis of the physiological results, we previously hypothesized that the GLP-1 exerts its inhibitory action on smooth muscle indirectly by activating nNOS-IR interneurons to produce NO, which, in turn, inhibits the acetylcholine release by the motor cholinergic ones. ${ }^{22}$ Presently, we have to imagine a diverse mechanism of action for the GLP-2 to inhibit muscle contraction. Indeed, GLP-2 would act directly on the nitrergic motor neurons increasing NO production responsible for muscle relaxation. This possibility fits well with the present physiological findings showing that the inhibitory effect induced by GLP-2 on spontaneous mechanical activity was blocked by TTX or L-NAME and exogenous GLP-2 was able to increase the nitrergic relaxation caused by EFS. 
In summary, our immunohistochemical and physiological findings indicate that the GLP-2 can exert an action on both excitatory and inhibitory neurons with opposite effects, negatively modulating the former and positively the latter ones. Different coupling between GLP-2R and G proteins could explain these opposite results. Indeed, a number of different cells transfected with the GLP-2R have been used to examine GLP-2R signaling. These studies have shown that GLP-2R receptor can couple to alternative $G$ proteins with consequent increase or decrease in the cAMP intracellular content ${ }^{11,12}$ and it is known that the increase in cAMP facilitates neurotransmitter release while its decrease inhibits this release. ${ }^{9,10,26}$ Moreover, it has been reported that GLP-2R couples in a dose-dependent manner to alternate $\mathrm{G}$ protein and cAMP accumulation occurs at moderate concentrations $(0.1-1 \mathrm{nmol}$ $\mathrm{L}^{-1}$ ), while cAMP reduction occurs at higher levels of GLP-2. ${ }^{2,6,27}$ In addition, our previous study showed that in mouse colon the inhibitory effects of GLP-2 on evoked cholinergic contractions were significantly inhibited by pertuxis toxin, a Gi/o protein inhibitor, supporting the hypothesis that the GLP-2R may be coupled to inhibitory G protein, ${ }^{6}$ while intestinal muscle strips and fetal rat intestinal cells, all of which express the endogenous GLP-2R, respond to GLP-2 treatment with an increase in cAMP. ${ }^{26-29}$ Therefore, it might be supposed that in our preparation the GLP-2R detected on inhibitory neurons binds to excitatory $G$ protein, while GLP-2R present on excitatory neurons recruits inhibitory $\mathrm{G}$ protein.
A special consideration deserves the presence of GLP-2R-IR nerve varicosities at the DMP. In fact, whereas no ICC shared the GLP-2R-IR, the great majority of the GLP-2R-IR inhibitory and excitatory varicosities were found surrounding the ICC-DMP. This ICC population is definitively recognized as the main target of enteric neurotransmission playing an intermediate role between the nervous system and the circular smooth muscle cells. Therefore, it is very likely that most of the GLP-2 mediated action needs the ICC-DMP recruitment. In support of this hypothesis there is the observation that exogenous GLP-2 failed to affect the mechanical activity of the longitudinal smooth muscle and no GLP-2R-immunoreactive nerve fiber was seen within the longitudinal muscle layer.

\section{ACKNOWLEDGMENTS}

This work was supported by a grant from Ministero dell'Istruzione, dell'Università e della Ricerca (PRIN 2007), Italy. We wish to thank Dr. M. Schemann for his generous gift.

\section{AUTHOR CONTRIBUTION}

The Authors contributed as follows: LC performed the immunohistochemical experiments; AR performed the functional experiments. M- G V and M-S F-P designed the research study and analyzed the data; FM contributed to design of the research study and to write the paper. M-G V wrote the paper.

\section{REFERENCES}

1 Drucker DJ, Erlich P, Asa SL, Brubaker PL. Induction of intestinal epithelial proliferation by glucagon-like peptide 2. Proc Natl Acad Sci USA 1996; 93: 7911-6.

2 Mortensen K, Christensen LL, Holst JJ, Orskov K. GLP-1 and GIP are colocalized in a subset of endocrine cells in the small intestine. Regul Pept 2003; 114: 189-96.

3 Theodorakis MJ, Carlson O, Michopoulos $\mathrm{S}$ et al. Human duodenal enteroendocrine cells: source of both incretin peptides, GLP-1 and GIP. Am I Physiol Endocrinol Metab 2006; 290: E550-9.

4 Wojdemann M, Wettergren A, Hartmann B, Holst JJ. Glucagon-like peptide-2 inhibits centrally induced antral motility in pigs. Scand I Gastroenterol 1998; 33: 828-32.
5 Amato A, Baldassano S, Serio R, Mulè F. Glucagon-like peptide-2 relaxes mouse stomach trough vasoactive intestinal peptide release. Am I Physiol Gastrointest Liver Physiol 2009; 296: G678-84.

6 Amato A, Rotondo A, Cinci L, Baldassano S, Vannucchi MG, Mulè F. Role of cholinergic neurons in the motor effects of glucagon-like peptide-2 in mouse colon. Am I Physiol Gastrointest Liver Physiol 2010; 299: G1038-44.

7 Meier JJ, Nauck MA, Pott A et al. Glucagon-like peptide 2 stimulates glucagon secretion, enhances lipid absorption, and inhibits gastric acid secretion in humans. Gastroenterology 2006; 130: 44-54.

8 Nagell CF, Wettergren A, Pedersen JF, Mortensen D, Holst JJ. Glucagon-like peptide 2 inhibits antral emptying in man, but is not a potent as glucagon- like peptide 1. Scand I Gastroenterol 2004; 39: 353-8.

9 Munroe DG, Gupta AK, Kooshesh F et al. Prototypic G protein-coupled receptor for the intestinotrophic factor glucagon like peptide 2. Proc Natl Acad Sci USA 1999; 96: 1569-73.

10 Yusta B, Somwar R, Wang $\mathrm{F}$ et al. Identification of glucagons-like peptide 2 (GLP-2)-activated signalling pathways in baby hamster kidney fibroblasts expressing the rat GLP-2 receptor. I Biol Chem 1999; 274: 30459-67.

11 Koeheler JA, Yusta B, Drucker DJ. The HeLa cell glucagons-like peptide2 receptor is coupled to regulation of apoptosis and ERK1/2 activation trough divergent signalling pathways. Mol Endocrinol 2005; 19: 459-73.

12 Rocha FG, Shen KR, Jasleen J et al. Glucagon-like peptide-2: divergent 
signalling pathways. I Surg Res 2004; 121: $5-12$.

13 Lovshin J, Estall J, Yusta B, Brown TJ, Drucker DJ. Glucagon-like peptide (GLP)-2 action in the murine central nervous system is enhanced by elimination of GLP-1 receptor signalling. I Biol Chem 2001; 276: 21489-99.

14 Velázquez E, Blázquez E, Ruiz-Albusac JM. Synergistic effect of glucagonlike peptide 2 (GLP-2) and of key growth factors on the proliferation of cultured rat astrocytes. Evidence for reciprocal upregulation of the mRNAs for GLP-2 and IGF-I receptors. Mol Neurobiol 2009; 40: 183-93.

15 Yusta B, Huang L, Munroe D et al. Enteroendocrine localization of GLP2 receptor expression in humans and rodents. Gastroenterology 2000; 119: 744-55.

16 Nelson DW, Sharp JW, Brownfield MS, Raybould HE, Ney DM. Localization and activation of glucagon-like peptide- 2 receptors on vagal afferents in the rat. Endocrinology 2007; 148: 1954-62.

17 Wallis K, Walters JRF, Forbes A. Review article: glucagon-like peptide 2 - current application and future directions. Aliment Pharmacol Ther 2007; 25: 365-72.

18 Guan X, Karpen HE, Stephensen J et al. GLP-2 Receptor localizes to enteric neurons and endocrine cells expressing vasoactive peptides and mediates increased blood flow. Gastroenterology 2006; 130: 15064.

19 Orskov C, Hartmann B, Poulsen SS, Thuelesen J, Hare KJ, Holst JJ. GLP-2 stimulates colonic growth via KGF, released by subepithelial myofibroblasts with GLP-2 receptors. Regul Pept 2005; 124: 105-12.

20 Bjerknes $M$, Cheng H. Modulation of specific intestinal epithelial progenitors by enteric neurons. Proc Natl Acad Sci USA 2001; 98: 12497 502.

21 Schemann M, Sann H, Schaff C, Mäder M. Identification of cholinergic neurons in enteric nervous system by antibodies against choline acetyltransferase. Am J Physiol 1993; 265: G1005-9.

22 Amato A, Cinci L, Rotondo A et al. Peripheral motor action of glucagonlike peptide- 1 trough enteric neuronal receptors. Neurogastroenterol Motil 2010; 22: 664-72.

23 Mulè F, Baffi MC, Cerra MC. Dual effect mediated by protease-activated receptors on the mechanical activity of rat duodenum. Eur I Pharamcol 2002; 136: 367-74.

24 Fornai M, Antonioli L, Colucci R et al. Emerging role of cyclooxygenase isoforms in the control of gastrointestinal neuromuscular functions. Pharmacol Ther 2010; 125: 62-78.
25 Fornai M, Antonioli L, Colucci R et al. Differential regulation of colonic excitatory nerve pathways by cyclooxygenase isoforms in diverticular disease. Italian group for the study of neuromorphology. GISN. Symposium: the future of enteric nervous system: between neurobiology and clinical applications. Bologna Italy 2010; 10-11.

26 Walsh NA, Yusta B, DaCambra MP, Anini Y, Drucker DJ, Brubacker PL. Glucagon-like peptide-2 receptor activation in the rat intestinal mucosa. Endocrinology 2003; 144: 4385-92.

27 Shin ED, Estall JL, Izzo A, Drucker DI, Brubaker PL. Mucosal adaptation to enteral 491 nutrients is dependent on the physiologic actions of glucagon-like peptide-2 in mice. Gastroenterology 2005; 128: 1340 53.

28 Anini Y, Izzo A, Oudit GY, Backx PH, Brubaker PL. Role of phoshatidylinositol-3 kinase- gamma in the actions of glucagons-like-peptide- 2 on the murine small intestine. Am I Physiol Endocrinol Metabol 2007; 292: E1599-606.

29 Dubè PE, Forse Cl, Baharami J, Brubaker PL. The essential role of insulin-like growth factor-1 in the intestinal trophic effects of glucagons-like-peptide-2 in mice. Gastroenterology 2006; 131: 589-605. 